\title{
EVALUATION OF SUCCESS OF RESIN INFILTRATION TECHNIQUE IN SUPERFICIAL PROXIMAL CARIOUS LESIONS OF POSTERIOR TEETH
}

\author{
Faisal Mahmood, Muhammad Bader Munir*, Ali Altaf*, Ajmal Yousaf, Faisal Bhangar, Syed Muzammil Hussain \\ Armed Forces Institute of Dentistry/National University of Medical Sciences (NUMS) Rawalpindi Pakistan, \\ *De'Montmorency College of Dentistry, Lahore Pakistan
}

\begin{abstract}
Objective: To determine the effectiveness of resin infiltration technique in arresting superficial proximal carious lesions of posterior teeth.

Study Design: Quasi experimental study.

Place and Duration of Study: Operative dentistry department, De' Montmorency College of Dentistry, Lahore Pakistan, from Oct 2018 to Mar 2019.

Methodology: Meeting inclusion criteria were selected. Informed consent was obtained. After application of rubber dam; etchant gel was applied to superficial proximal carious lesions in these patients; water-rinsed and air-dried for $30 \mathrm{sec}$; resin was then infiltrated into each lesion. Patients were recalled after 6 months for follow up.

Results: Total patients were 30 out of which $18(60 \%)$ were males and $12(40 \%)$ were females. Mean age of patients was 25.77 years ranging from 16-35 years. Success of resin infiltration technique in superficial proximal carious lesions in posterior teeth was $86.7 \%$ measured by bitewing radiograph taken on follow up after 6 months to see any progression of carious lesion.

Conclusion: Resin infiltration was effective in $86.7 \%$ patients in arresting progress of superficial proximal carious lesions with no significant difference for age and gender. Hence it is suggested that resin infiltration being promising micro invasive approach should be considered in addition to non-operative and operative treatment approaches.
\end{abstract}

Keywords: Minimally invasive restoration, Resin infiltration, Superficial proximal carious lesion.

This is an Open Access article distributed under the terms of the Creative Commons Attribution License (https://creativecommons.org/licenses/by-nc/4.0/), which permits unrestricted use, distribution, and reproduction in any medium, provided the original work is properly cited.

\section{INTRODUCTION}

Dental caries is a major and common disease affecting oral cavity hard tissues. It results in localized demineralization and loss of tooth structure ${ }^{1,2}$. However, at very initial stages loss of tooth structure occurs beneath an apparently intact but micro-porous enamel surface which gives characteristic opaque, matt appearance called white spot lesion ${ }^{1,3}$. This is first clinical sign for detection of caries process which, at this stage, can be slowed down or even stopped completely by non-operative measures ${ }^{4}$. Therefore, early diagnosis and management of white spot lesion is extremely important. Superficial proximal carious lesions may remain undetected as proximal surfaces are not visible on clinical examination ${ }^{5}$. With favourable factors for caries progression, initial lesions with intact surface layer ultimately leads to cavitation ${ }^{6}$.

Cavitation of enamel surface warrant invasive treatment methods. Proximal lesions are particularly not accessible to instrumentation due to anatomic location. Cavity preparation results in collateral damage which is very high because large amounts of healthy tooth tissue have to be sacrificed to gain access to these

Correspondence: Dr Faisal Mahmood, Department of Consultant Operative, Armed Forces Institute of Dentistry, Rawalpindi Pakistan Received: 11 May 2020; revised received: 28 Jun 2020; accepted: 01 Jul 2020 lesions and a circle of treatment and retreatment begins with first invasive intervention?

Early diagnosis and individual caries risk assessment forms the basis for management of caries with either invasive, minimally invasive or non-invasive methods. Along with prevention like regular cleaning of teeth, low-sugar diet and recommended amount of fluoride ${ }^{8,9}$, preservation of dental structure and avoidance of surgical treatment are thus major treatment goals. So, in recent decades, non-invasive or recently micro invasive method for treatment of early proximal carious lesion are becoming more popular to avoid need of restoration ${ }^{6}$.

Sealants have been used on non-cavitated occlusal pits and fissure caries as a minimally invasive method to reduce lesion progression. They have been proven to prevent further tooth decay by acting as diffusion barrier to acid ${ }^{1,6}$. But sealants do not effectively seal pores within the body of the lesion and barrier is created only on the surface ${ }^{1,2}$. Thus, there has been a lack of effective procedure for arresting caries progression in one session.

An alternative approach can be then to stop progression of carious lesions by infiltrating these pores with low viscosity light curing resin thus forming diffusion barrier inside the lesion. In this context, a 
new treatment modality to arrest progression of initial carious lesion without use of dental drill has been suggested. It is a novel treatment option for these lesions with intact tooth surface and will help in bridging the gap between non-invasive and minimally invasive treatment options of initial dental caries, thus possibly delaying the first placement of restoration ${ }^{1,6,7}$. The aim of caries infiltration is to soak up the porous lesion body with a low viscosity light polymerising resin (infiltrant) that is subsequently hardened by blue light ${ }^{7}$.

The principal features of this technique are that it is micro invasive, preserves tooth structure, arrest lesion progression, obturate porous deeply demineralized area, has high patient acceptance and can be completed in single visit ${ }^{3,6}$.

So far various international studies have been conducted on this new treatment option and with various sample sizes. No local study has been done up till now to check the efficacy of this technique in our population. Objective of the present research was to determine the success of this new resin infiltration technique in arresting superficial proximal carious lesions in posterior teeth in patients presented to our dental hospital.

\section{METHODOLOGY}

This quasi experimental study was conducted at department of Operative Dentistry, de' Montmorency College of Dentistry/Punjab Dental Hospital Lahore, from October 2018 to March 2019 after approval from institutional review board certificate number 1525/ DCD. Lesion on mesial or distal surface of a tooth with an intact enamel surface detected as a radiolucent area involving enamel that may extend up to dentin on a bitewing radiograph was defined as superficial proximal carious lesion. Sample size of 30 patients between 16-35 years of age were selected from both genders using non probability consecutive sampling technique. Sample size was calculated using WHO calculator with 95\% confidence level, 10\% margin of error and taking expected percentage of success i.e. $91 \%{ }^{11}$, of resin infiltration technique. After detailed history and clinical examination, patients with poor oral hygiene presenting with calculus, gingivitis or periodontitis, multiple missing posterior teeth, removable partial denture or fixed bridges and handicapped patient were excluded from study. Bitewing radiographs were made with individually customized $\mathrm{XCP}{ }^{\circledR}$ film holders and standard parameters of taking radiograph. Only one superficial proximal carious lesion extending radiographically either to inner enamel or outer third of dentin was selected from each patient. The parameters and equipment which were usedduring diagnostic radiograph were noted in each patient's proforma so to make follow up radiographs comparable.

Teeth were isolated with rubber dam and specially designed wedges were placed between the teeth to be treated. The applicator was then placed into interdental area and Icon etch gel (Icon® DMG Germany) containing $15 \%$ hydrochloric acid was applied for two minutes on affected proximal area. The site was rinsed thoroughly for 30 seconds and then icon dry (Icon ${ }^{\circledR}$ DMG Germany) was applied containing 99\% ethanol to facilitate dehydration of area. The new proximal tip was then screwed onto the icon infiltrant syringe containing low viscosity resin and applied to treatment area. The green side of proximal tip was aligned to surface being treated. The low viscosity icon resin was then applied in ample amount by turning piston into shaft of syringe. The infiltrant was then allowed to penetrate into body of lesion through demineralized surface and pores created by etchant. Applicator syringe was slightly moved to enhance infiltration by capillary action and small amount of material was added during this process. During first application this low viscosity resin was left in place for 3 minutes. Application tip was then removed. Before polymerization by light dental floss was used to remove excess resin infiltrant. The low viscosity resin was then light cured from three different directions for 40 seconds. A new proximal-tip was then taken and applied to same infiltrant syringe. Second application of resin was then done by following same procedure but this time resin was left in place for one minute to penetrate. Light curing was done from occlusal, lingual and buccal sides for 40 seconds after removing excess resin by floss. Wedge and rubber dam were removed and polishing strips were used for surface finish. To check the effectiveness of resin infiltration technique, a clinical and radiographic follow-up was initiated and compared with baseline investigation made preoperatively to detect any progression of carious lesions after 6 months. Bitewing radiographs were taken using same customized film holders and equipment which were used in diagnostic radiograph. The data was collected on a structured proforma by the researcher and was analyzed.

Data was entered and analyzed by SPSS version 18. Mean \pm standard deviation for quantitative variables and frequency and percentage for qualitative variables were calculated. chi-square test was applied with $p$-value $\leq 0.05$ as significant. 


\section{RESULTS}

Out of total 30 patients, $18(60 \%)$ were males while 12 (40\%) were females. Age ranged from 16-35 years with mean age $25.77 \pm 4.59$ years. Eleven $(36.7 \%)$ patients were $<25$ while $19(63.3 \%)$ were $>25$ years of age (table-I).

Patients were called for follow up after 6 months and clinical and radiographic examination was carried out. Resin infiltration technique was taken as successful if: i). There was no progression of caries into cavitation clinically and enamel surface remained intact as seen preoperatively: ii). There was no radiological progression of lesion compared with baseline bitewing radiograph taken preoperatively.

On radiographic and clinical examination during follow up after 6 months, 4 (13.3\%) carious lesions out of 30 showed radiological progression when compared with baseline radiograph, therefore not meeting success criteria according to operational definition. So, success of resin infiltration technique in superficial proximal carious lesions in posterior teeth was $86.7 \%$ (table-II).

Table-I: Descriptive statistics of gender and group age.

\begin{tabular}{c|c|c|c}
\hline \multicolumn{2}{c}{} & \multicolumn{2}{|c}{ Group Age } \\
\cline { 3 - 4 } \multicolumn{2}{c|}{} & <25 Years & $>25$ Years \\
\hline \multirow{2}{*}{ Gender } & Male & $7(23.3 \%)$ & $11(36.7 \%)$ \\
\cline { 2 - 4 } & Female & $4(13.3 \%)$ & $8(26.7 \%)$ \\
\hline
\end{tabular}

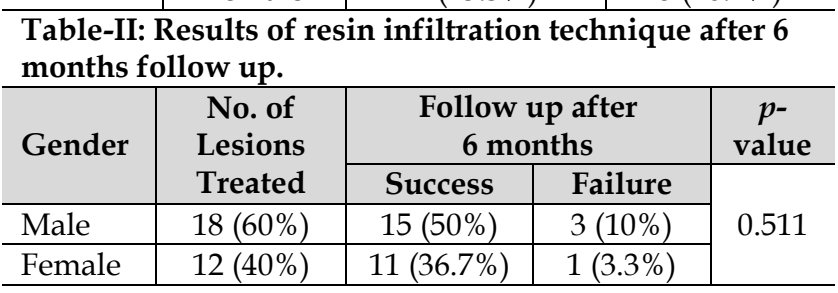

\section{DISCUSSION}

Resin infiltration is considered as a micro-invasive approach for treatment of non cavitated superficial proximal carious lesion ${ }^{12}$. Proximal surfaces of teeth are second more prone to caries due to increase chances of food impaction and inability to properly clean interproximal area by conventional cleaning aids $^{13}$. Carious lesions on proximal surfaces at initial stages go unnoticed until either an obvious cavitation occurs or seen by chance on radiographic examination. At these initial stages' preventive or non-invasive approaches such as fluoride application, use of CPP-ACP, oral hygiene measures and dietary advice will strictly depend upon compliance of patient ${ }^{14,15}$. Resin infiltration is employed to create a diffusion barrier inside of lesion surface with simplified clinical application ${ }^{3}$. It is a promising micro-invasive treatment option and it will be considered as an added option to conventional non-invasive and invasive treatment approaches. It provides simplified clinical application in one visit thus least dependant on patient compliance which otherwise required in other non-invasive approaches.

In our study, there were thirty patients in total out of which $60 \%$ were male. Males predominated over females in this study as frequency of male patients visiting Punjab dental hospital is higher than females. However, in a study done by Paris et $a l^{7}$, percentage of female patients included in study was $64 \%$ which was higher than our study. Similarly, some more international studies showed higher female participation ${ }^{16}$.

Mean age of patients participating in this study was $25.7 \pm 4.5$ years which was similar to study done by Paris et $a l^{7}$. While study on resin infiltration by Martignon et $a l^{10}$, mean age of participants was 21 years. In his study age range was 21-31 years while in our study age range was 16-35 years. Another study by Ekstrand et al 17 was conducted on children with mean age of 7.17 \pm 0.68 years.

Success of resin infiltration technique was $86.7 \%$ in our study which is very similar to study conducted by Martignon et al ${ }^{10}$, in which success was $84.2 \%$ on radiographic examination. Martignon also evaluated results by digital subtraction radiography with $75.4 \%$ success. They concluded that this method is more sensitive than pair wise radiography but also stated that in normal clinical settings radiographic examination is a simpler method. Furthermore, they evaluated results even after 3 years and where success was $67 . \%^{10}$. This decline in success was due to long term follow up. Similarly, a study by Abuchaimet et al, also showed $84 \%$ success of sealing proximal carious lesion ${ }^{18}$. Paris et $a l^{7}$, also evaluated efficacy of resin infiltration technique by radiographic lesion progression and by digital subtraction radiography. According to his study $96 \%$ of carious lesion showed no progression by radiographic examination which is higher than our study while with digital subtraction radiography, he showed $93 \%$ success of resin infiltration technique ${ }^{7}$.

Ekstrand et al showed in their study that only $23.1 \%$ carious lesion showed progression which also showed success of this technique even in children ${ }^{17}$. Altarabulsi et al ${ }^{19}$, also evaluated resin infiltration technique and only 2 carious lesions showed progression after this technique. Success of resin infiltration technique was $95.3 \%$ in his study which is much higher than our study but similar to Paris et al. research ${ }^{7,19}$. 
In our study, effect of other variables was also checked such as gender or age on success of resin infiltration which showed insignificant relationship with both these variables. No clinical problems occurred during use of this technique showing good clinical quality and safety of resin infiltration. Regarding the remedial and preventive effect of resin infiltration of superficial proximal caries, the results showed the success of resin infiltration in hampering caries progression ${ }^{18}$.

The reasons for minor failures of resin infiltration during different studies were described by different authors as inability to achieve effective isolation and control of saliva, poor diagnosis leading to minor cavitation gone unnoticed before proximal sealing or resin infiltration, and the most important reason is that it is hard to be certain that the resin has absolutely provided the barrier or infiltrated the carious lesion ${ }^{11,14}$. Selection of patient on the basis of caries risk assessment is also important as high caries risk may also play an important part in failures. Despite the fact that failures can occur, proximal resin sealing and proximal resin infiltration will now have a place in the treatment of superficial proximal carious lesions in the present and future era of dentistry due to higher percentages of success ${ }^{16-19}$.

\section{CONCLUSION}

Results of our study confirm resin infiltration technique arrests the progression of non-cavitated caries lesions. This suggests resin infiltration technique is a promising treatment option in addition to non-invasive and invasive approaches. However, case selection, proper diagnosis, right management of case and correct application technique is important in choosing this ultraconservative treatment option. Failure may occur if patient high caries risk and inability to achi to perform procedure is not taken into account.

\section{CONFLICT OF INTEREST}

This study has no conflict of interest to be declared by any author.

\section{REFERENCES}

1. Peters MC, Hopkins AR Jr, Zhu L, Yu Q. Efficacy of proximal resin infiltration on caries inhibition. Results from a 3-year randomized controlled clinical trial. J Dent Res 2019; 98(13): 1497-02.

2. Chatzimarkou S, Koletsi D, Kavvadia K. The effect of resin infiltration on proximal caries lesions in primary and permanent teeth. A systematic review and meta-analysis of clinical trials. J Dent 2018; 77(2): 8-17.

3. Ntovas P. A clinical guideline for caries infiltration of proximal enamel lesions with resins. Br Dent J 2018; 225(4): 299-304

4. Zhao $X$, Ren YF. Surface properties and color stability of resininfiltrated enamel lesions. Oper Dent 2016; 41(6): 617-26.

5. Liang Y, Deng Z, Dai X, Tian J, Zhao W. Micro-invasive interventions for managing non-cavitated proximal caries of different depths: A systematic review and meta-analysis. Clin Oral Investigat 2018; 22(8): 2675-84.

6. Ciftci ZZ, Hanimeli S, Karayilmaz H, Gungor OE. The efficacy of resin infiltrate on the treatment of white spot lesions and developmental opacities. Niger J Clin Pract 2018; 21(11): 1444-49.

7. Paris S, Hopfenmuller W, Meyer-Lueckel H. Resin infiltration of caries lesions: an Efficacy Randomized Trail. J Dent Res 2010; 89(8): 823-26.

8. Suga USG, Terada RSS, Ubaldini ALM, Fujimaki M, Pascotto RC, Batilana AP, et al. Factors that drive dentists towards or away from dental caries preventive measures: systematic review and metasummary. PloS one 2014; 9(10): e107831-34.

9. Segura A, Boulter S, Clark M, Gereige R, Krol DM, Mouradian $\mathrm{W}$, et al. Maintaining and improving the oral health of young children. Pediatrics 2014; 134(6): 1224-29.

10. Martignon S, Ekstrand KR, Gomes J, Lara JS, Cortes A. Infiltrating/sealing proximal caries lesions: a 3-year randomized clinical trail. J Dent Res 2012; 91(3): 288-92.

11. Rossiza I. Kabakchieva, Natalia H, Gateva1, Hristina D. Nonoperative treatment of non-cavitated approximal carious lesions of permanent children's teeth. J IMAB 2014; 20(2): 626-30.

12. Manoharan V, Kumar SA, Arumugam SB, Anand V, Krishnamoorthy S, Methippara JJ. Is resin infiltration a microinvasive approach to white lesions of calcified tooth structures?: a systemic review. Int J Clin Pediatr Dent 2019; 12(1): 53-58.

13. Checinska IW, Mojsym A, Maczulska AL, Chalas R. Specifics of proximal caries and their diagnostics in posterior teeth. Pharm Med Sci 2015; 28(2): 92-96.

14. Kidd EAM, Fejerskov O. Prevention of dental caries and the control of disease progression: concepts of preventive, non-operative treatment. In: Fejerskov O, Kidd EAM, editors. Dental caries: The Disease and its clinical Management. Oxford: Blackwell Publishing Ltd; 2003. p.167-169.

15. Holmgren C, Gaucher C, Decerle N, Doméjean S. Minimal intervention dentistry II: part 3. Management of non-cavitated (initial) occlusal caries lesions-non-invasive approaches through remineralisation and therapeutic sealants. Br Dent J 2014; 216(5): 237-43.

16. Ekstrand K, Martignon S, Bakhshandeh A, Ricketts DN. The nonoperative resin treatment of proximal caries lesions. Dent Update 2012; 39(9): 614-22.

17. Ekstrand KR, Bakhshandeh A, Martignon S. Treatment of proximal superficial caries lesions in primary molar teeth with resin infiltration and fluoride varnish versus fluoride varnish only: Efficacy after 1 year. Caries Res 2010; 44(1): 41-46.

18. Doméjean S, Ducamp R, Léger S, Holmgren C. Resin infiltration of non-cavitated caries lesions: a systematic review. Med Princ Pract 2015; 24(3): 216-21.

19. Altarabulsi MB, Alkilzy M, Petrou MA, Splieth C. Clinical safety, quality and effect of resin infiltration for proximal caries. Eur J Paediatr Dent 2014; 15(1): 39-44. 